\title{
Growth and endocrine function in steroid sensitive nephrotic syndrome
}

\author{
L REES, S A GREENE, P ADLARD,${ }^{*}$ J JONES, ${ }^{*}$ G B HAYCOCK, S P A RIGDEN, M PREECE, ${ }^{*}$ \\ AND C CHANTLER
}

Evelina Children's Hospital, United Medical and Dental Schools of Guy's and St Thomas's Hospitals, Guy's Hospital and ${ }^{*}$ Department of Growth and Development, Institute of Child Health, London

SUMMARY Longitudinal height data and physical development were assessed in 29 boys and 12 girls taking long term steroid treatment for steroid sensitive nephrotic syndrome. Growth in both boys and girls, assessed by changes in height standard deviation score ( $\Delta$ Ht SDS), worsened significantly with chronological age. There was a significant negative correlation between $\Delta \mathrm{Ht}$ SDS and duration of treatment in boys, but not in girls. There was no correlation between $\Delta \mathrm{Ht}$ SDS and relapse rate or the use of cyclophosphamide. In the boys, Ht SDS decreased significantly only after the age of 10 years and was associated with delay in the appearance of secondary sexual characteristics.

Eight adolescent boys were assessed endocrinologically by an overnight hormone profile. Blunting of the pulsatility of growth hormone and gonadotrophins was seen in six. Normal profiles were seen in two subjects who were both off steroid treatment at the time of study.

Abnormal endocrine function in adolescent boys treated long term for steroid sensitive nephrotic syndrome corresponded with the clinical picture of delayed onset of puberty, which accounted for severe growth retardation in a substantial proportion of subjects.

The adverse effects of steroid treatment on growth have been related to both dosage and duration of treatment. ${ }^{1-3}$ Many children with steroid sensitive nephrotic syndrome receive steroid treatment for several years and in many cases treatment continues throughout adolescence. ${ }^{4}$ Current practice for long term treatment is to use a single dose of prednisolone on alternate mornings. This regimen has been suggested to minimise growth retardation and to leave final height unaffected ${ }^{5-7}$; 'catch-up' growth has been reported after treatment is stopped. ${ }^{8}$

We have observed, however, several adolescents taking long term alternate day steroids for steroid sensitive nephrotic syndrome who were significantly short or whose sexual maturation was delayed,or both, and who, as a result, were severely emotionally disturbed. Retrospective analysis of the longitudinal growth patterns of subjects currently attending our paediatric renal clinic with this syndrome, suggested that after the age of 10 years maturational delay was a prominent clinical feature. We therefore investigated the endocrine function of boys with steroid sensitive nephrotic syndrome in an attempt to determine the site of action of steroids on the hypothalamic-pituitary-gonadal axis, which may account for delayed puberty and subsequent short stature.

\section{Patients and methods}

All the subjects with steroid sensitive nephrotic syndrome who were steroid dependent and attended Guy's Hospital paediatric renal clinic between July 1984 and January 1986 were included in the study (total 41: 29 boys, 12 girls). Relapses of proteinuria were treated with prednisolone $\left(60 \mathrm{mg} / \mathrm{m}^{2} /\right.$ day $)$ and maintenance steroids were given on alternate days at the dose found to be necessary to keep the urine protein free. An eight week course of cyclophosphamide $(2 \cdot 5-3 \mathrm{mg} / \mathrm{kg} / \mathrm{day})$ was given to children who required unacceptably high doses of maintenance steroids to prevent relapse. All subjects had normal plasma creatinine concentrations.

The following were obtained from the notes and at examination:

(1) Chronological age (year) at diagnosis, at first clinic visit to Guy's Hospital (14 boys and four girls were seen initially at other hospitals), 
and at most recent height measurement (table 1).

(2) First available height measurement at Guy's Hospital (first $\mathrm{Ht}$ ) and subsequently at yearly intervals until the most recent examination or at the time of stopping steroid treatment (last $\mathrm{Ht}$ ). Height was measured by the clinic nurse using a Harpenden stadiometer. For each height $(\mathrm{cm})$ the height standard deviation score (Ht SDS) was calculated according to the formula, Ht $\mathrm{SDS}=\mathrm{x}-\overline{\mathrm{x}} / \mathrm{SD}$, where $\overline{\mathrm{x}}$ and $\mathrm{SD}$ are the age matched population mean height and standard deviation respectively and $\mathrm{x}$ is the patient's height (population data according to Tanner et $\left.a l^{9}\right)$.

(3) Duration of treatment calculated as the number of years on steroid treatment between first and last height measurements (table 1). (4) The number of relapses between first and last height measurement. A relapse was defined as an episode of proteinuria treated with an increase in prednisolone treatment to $60 \mathrm{mg} / \mathrm{m}^{2} /$ day.

(5) The number of courses of cyclophosphamide treatment.

(6) Pubertal staging (according to Tanner ${ }^{10}$ ) in those patients still attending Guy's Hospital.

Statistical differences between first and last $\mathrm{Ht}$ SDS were analysed by comparison of $95 \%$ confidence intervals. The change in Ht SDS from first to last measurements $(\Delta \mathrm{Ht}$ SDS) was correlated with age at final examination, duration of treatment, and the relapse rate by Pearson's product-moment correlation coefficient. The Mann-Whitney $U$ test was used to compare $\Delta \mathrm{Ht}$ SDS in those children treated and those not treated with cyclophosphamide; to compare both the relapse rate and the change in $\mathrm{Ht}$ SDS before and after the age of 10 years; and to compare $\Delta \mathrm{Ht}$ SDS in boys age less than 8 years at final examination with boys who began treatment after the age of 8 years. Results are expressed as mean (SD).

An overnight hormone profile study was performed in eight adolescent boys who were short or delayed in puberty, or both. Three boys were off steroid treatment and clinically well with no proteinuria. Each study commenced at 1800 hours, when an indwelling cannula was inserted into a forearm vein. Adequacy of sleep was analysed using a portable continuous electroencephalograph (Oxford Medilog System). ${ }^{11}$ Blood samples were taken every 20 minutes from 2000 hours through to 0700 hours ( $3 \mathrm{ml}$ blood per sample). Plasma was subsequently stored at $-20^{\circ} \mathrm{C}$ until assay. Growth hormone $(\mathrm{mU} / \mathrm{l})$ and gonadotrophins (luteinising hormone and follicle stimulating hormone IU/l) were measured in each sample and testosterone $(\mathrm{nmol} / \mathrm{l})$ and insulin like growth factor I (IGF-1, U/ml) in intermittent samples throughout the night. All samples from each profile were batch analysed.

Growth hormone was measured by radioimmunoassay using the first International Reference Preparation (IRP) reference 66/217, with intra-assay coefficient of variation of $5 \cdot 0 \%$ and $2.4 \%$ at 10.8 and $20.4 \mathrm{mU} / \mathrm{l}$ respectively and interassay coefficient of variation of $10.1 \%$ at $7.5 \mathrm{mU} / \mathrm{l}$. Gonadotrophins were measured by radioimmunoassay using the first IRP reference of luteinising hormone, 68/40 and follicle stimulating hormone, $78 / 549$, with an intraassay coefficient of variation of (a) luteinising hormone, $8.3 \%$ and $10 \%$ at 2.4 and $15.0 \mathrm{IU} / \mathrm{l}$, respectively and (b) follicle stimulating hormone, $10.3 \%$ and $7.3 \%$ at 2.8 and $14.9 \mathrm{IU} / \mathrm{l}$; testosterone was measured by radioimmunoassay using a standard kit method (Diagnostic Products Corporation). Serum IGF-1 was measured by radioimmunoassay after acid-ethanol extraction. ${ }^{12}$ Antiserum R557A and ${ }^{125} \mathrm{I}-\mathrm{IGF}-1^{13}$ were kindly provided by Dr D J Morrell (Institute of Child Health, London). Intra-assay and interassay coefficients of variation were $<8 \%$ and $<10 \%$ respectively. IGF- 1 values are expressed as potency relative to pooled normal adult human reference serum defined as 1 unit IGF $-1 / \mathrm{ml}$.

Growth hormone and gonadotrophin hormone peak analysis was performed both visually and using the 'Pulsar' programme ${ }^{14}$ which was modified locally to include a calculation of area under the curve by summation of trapezoids. Statistical comparison of the association of overnight profile measurements

Table 1 Median (range) age at diagnosis and at first and last examination and duration of treatment

\begin{tabular}{|c|c|c|}
\hline & Boys $(n=29)$ & Girls $(n=12)$ \\
\hline Age at diagnosis (years) & $3 \cdot 1(1 \cdot 3-13 \cdot 5)$ & $3.0(1.6-9.0)$ \\
\hline Age at first height measurement (years) & $4 \cdot 3(2 \cdot 0-13 \cdot 6)$ & $3.5(1 \cdot 6-7 \cdot 8)$ \\
\hline Age at last height measurement or & & \\
\hline on stopping steroids (years) & $13 \cdot 1(3 \cdot 5-18 \cdot 6)$ & $7 \cdot 3(4 \cdot 1-12 \cdot 9)$ \\
\hline $\begin{array}{l}\text { Duration of treatment over which heights } \\
\text { known (years) }\end{array}$ & $6 \cdot 2(0 \cdot 2-11 \cdot 5)$ & $3.6(0.6-9.2)$ \\
\hline
\end{tabular}


Table 2 Mean height standard deviation score (Ht SDS) for boys and girls at first and last examination compared with expected normal population data

\begin{tabular}{|c|c|c|c|c|c|}
\hline & \multirow{2}{*}{$\begin{array}{l}\text { No of } \\
\text { patients }\end{array}$} & \multirow[t]{2}{*}{ Mean $(S D)$} & \multirow{2}{*}{$\begin{array}{l}95 \% \text { Confidence } \\
\text { intervals }\end{array}$} & \multicolumn{2}{|c|}{ Normal population } \\
\hline & & & & $t$ & p Value \\
\hline $\begin{aligned} \text { Boys: first } \\
\text { last }\end{aligned}$ & $\begin{array}{l}29 \\
29\end{array}$ & $\begin{array}{l}-0.39(1.20) \\
-0.86(1.20)\end{array}$ & $\begin{array}{rr}-0.84 \text { to } 0.07 \\
-1.31 \text { to }-0.41\end{array}$ & $\begin{array}{l}-2 \cdot 10 \\
-4 \cdot 63\end{array}$ & $\begin{array}{c}0.05 \\
<0.001\end{array}$ \\
\hline $\begin{aligned} \text { Girls: first } \\
\text { last }\end{aligned}$ & $\begin{array}{l}12 \\
12\end{array}$ & $\begin{array}{l}-0.39(0.74) \\
-0.49(0.73)\end{array}$ & $\begin{array}{l}-0.86 \text { to } 0.08 \\
-0.96 \text { to } 0.02\end{array}$ & $\begin{array}{l}-1 \cdot 83 \\
-2 \cdot 34\end{array}$ & $\begin{array}{l}0.09 \\
0.04\end{array}$ \\
\hline
\end{tabular}

with other hormone values and staging of puberty was made by calculation of Pearson productmoment correlation coefficient.

\section{Results}

The mean Ht SDS for the first and last examination compared with normal population data is shown in table $2 .{ }^{9}$ There was a significant fall in the Ht SDS for the boys $(\Delta \mathrm{Ht}$ SDS $-0.47,95 \%$ confidence intervals -0.84 to -0.11 , df $28, \mathrm{t}-2.66, \mathrm{p}<0.02$ ) but not for the girls ( $\Delta \mathrm{Ht}$ SDS, $-0.10,95 \%$ confidence intervals -0.44 to 0.24 , df $11, t-0.66$, $\mathrm{p}=0 \cdot 5)$.

There was a significant negative correlation between $\Delta \mathrm{Ht}$ SDS and age at final examination (boys, $\mathrm{r}=-0.50, \mathrm{p}<0.01$, girls $\mathrm{r}=-0.61, \mathrm{p}<0.05$ ); (fig 1 ).

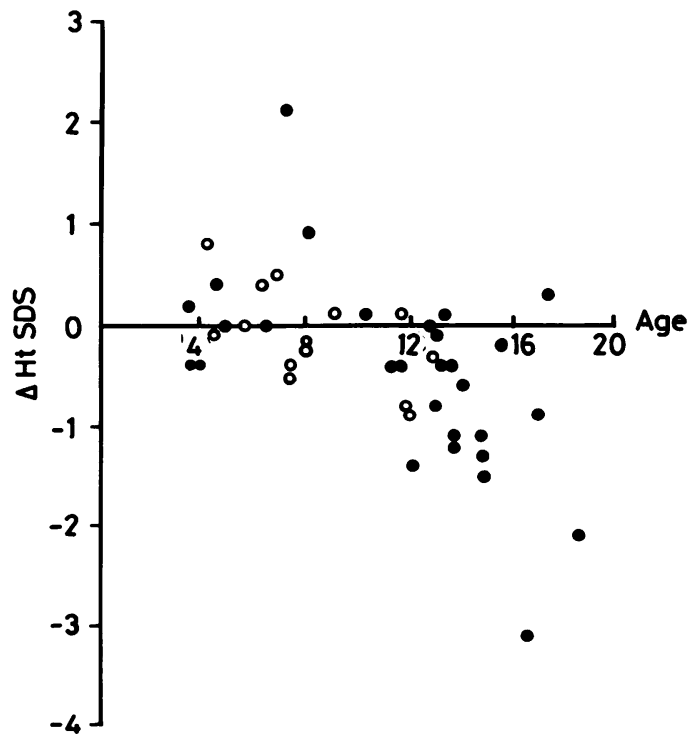

Fig 1 Relation between age (in years) at last examination and change in height standard deviation score ( $\triangle H t S D S)$ in boys (O) and girls (O).
There was also a significant negative correlation between $\Delta \mathrm{Ht}$ SDS and duration of treatment (fig 2) for the boys $(\mathrm{r}=-0.64, \mathrm{p}<0.01)$ but not the girls $(r=-0 \cdot 24, p=0 \cdot 5)$. Only three girls, however, had been treated for more than five years.

To attempt to clarify the relative effects of age and duration of treatment we examined the data longitudinally. The $\Delta \mathrm{Ht}$ SDS from first height at roughly yearly intervals is shown in fig 3 . The mean fall in Ht SDS after the age of 10 years until final examination was significantly greater than the fall in Ht SDS from first height measurement until the age of 10 years for the boys $(F=10 \cdot 25, \mathrm{p}<0 \cdot 01)$, but the difference was not significant for the girls $(F=4 \cdot 06$, $\mathrm{p}<0 \cdot 1)$. Only five boys developed steroid sensitive nephrotic syndrome over the age of 8 years (mean $11 \cdot 0$ years, range $8 \cdot 1-13 \cdot 6$ ) and required treatment until they were over 13 years; their mean age at final examination was 14.6 years (range 13.3-16.4) and mean $\Delta \mathrm{Ht}$ SDS was -0.6 (range -0.3 to $-1 \cdot 1$ ). There were seven boys who were less than 8 years

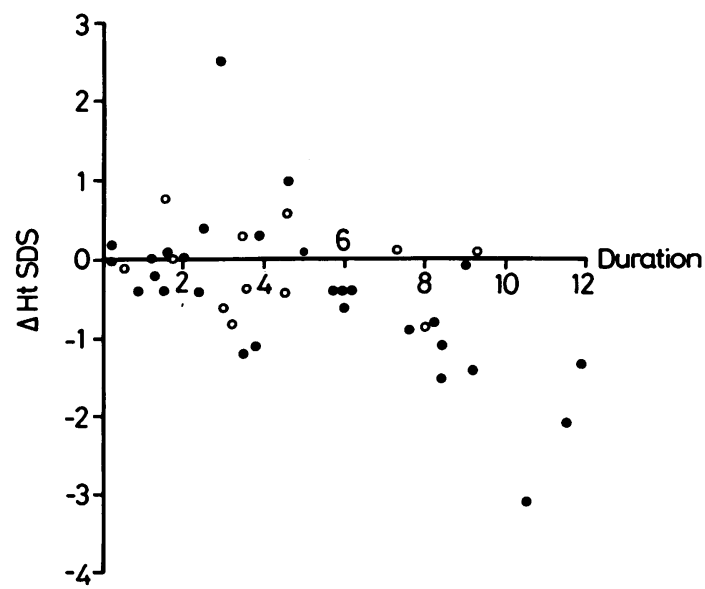

Fig 2 Relation between duration of treatment (in years) and change in height standard deviation score $(\triangle H t S D S)$ in boys (O) and girls $(\mathrm{O})$. 
old at final examination (mean 4.9 years, range 3.5-7.9) who had been treated for a mean of 1.9 years (range $0 \cdot 5-4 \cdot 0$ ). Their mean $\Delta \mathrm{Ht}$ SDS was $+0 \cdot 3$ (range $-0 \cdot 4-2 \cdot 1$ ). $\Delta \mathrm{Ht}$ SDS was significantly less for those diagnosed under 8 years of age than for the boys diagnosed after the age of 8 years $(F=6 \cdot 24, \mathrm{p}<0 \cdot 05)$

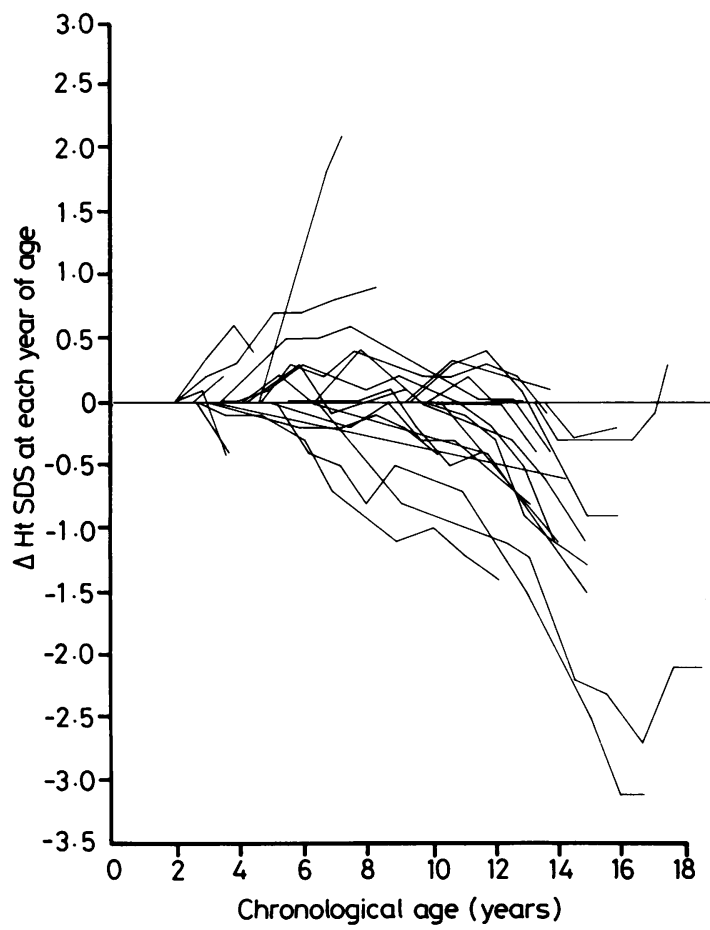

Fig 3 Effect of chronological age at taking steroids on change from initial Ht SDS (plotted at ' $O$ ' at age of first examination) at roughly yearly intervals (boys).
There was no relation between $\Delta \mathrm{Ht}$ SDS and the relapse rate for the boys $(r=0 \cdot 26, p=0 \cdot 5)$ or the girls $(r=0 \cdot 23, p=0 \cdot 5)$. The relapse rate was significantly greater before the age of 10 years for the boys $(F=6.44, \mathrm{p}<0.05)$ but was unchanged in the girls $(F=0 \cdot 01, \mathrm{p}>0 \cdot 1)$. There was no difference between the mean $\Delta \mathrm{Ht}$ SDS for boys treated with cyclophosphamide $(-0.79(1.03), \mathrm{n}=12)$ compared with those treated only with steroids $(-0.10(0.78) \mathrm{n}=17)$, $(F=2 \cdot 67, \mathrm{p}<0 \cdot 1)$.

Puberty was assessed in all the subjects and a comparison was made with the expected age at the appearance of secondary sex characteristics. ${ }^{10}$ Nine boys were delayed (mean age 15.2 years, range 14.1-16.7) with pubic hair and genital stages at less than the third centile, and testicular volume was between 4 and $10 \mathrm{ml}$ in seven. The three girls over the age of 12 years were progressing normally through puberty.

Demographic data and hormone profile analysis of the eight boys is given in table 3 . All subjects slept throughout the study with normal electroencephalographic sleep patterns. ${ }^{11}$ Data of hormone profiles from a control group were lacking. Various studies over the last 15 years, however, have suggested a noticeable increase in pulsatility of growth hormone and gonadotrophins during the age range associated with normal puberty. ${ }^{15-19}$ Visual comparison with these documented hormone profiles suggested that six of the eight subjects had an abnormal blunting of their overnight profiles, with a decrease in pulse amplitude but not pulse number. A typical example of a blunted profile is shown (fig 4a). Two of the boys not receiving steroids had higher concentration of hormones during the night as assessed visually and by pulse analysis (table 3 ). One of the boys, the subject who had been off steroids for two years, had exceptionally high concentrations of growth hor-

Table 3 Demographic data and overnight hormone analysis of growth hormone, luteinising hormone, testosterone, and insulin like growth factor-1 (IGF-1) from eight boys treated with long term steroid treatment for nephrotic syndrome

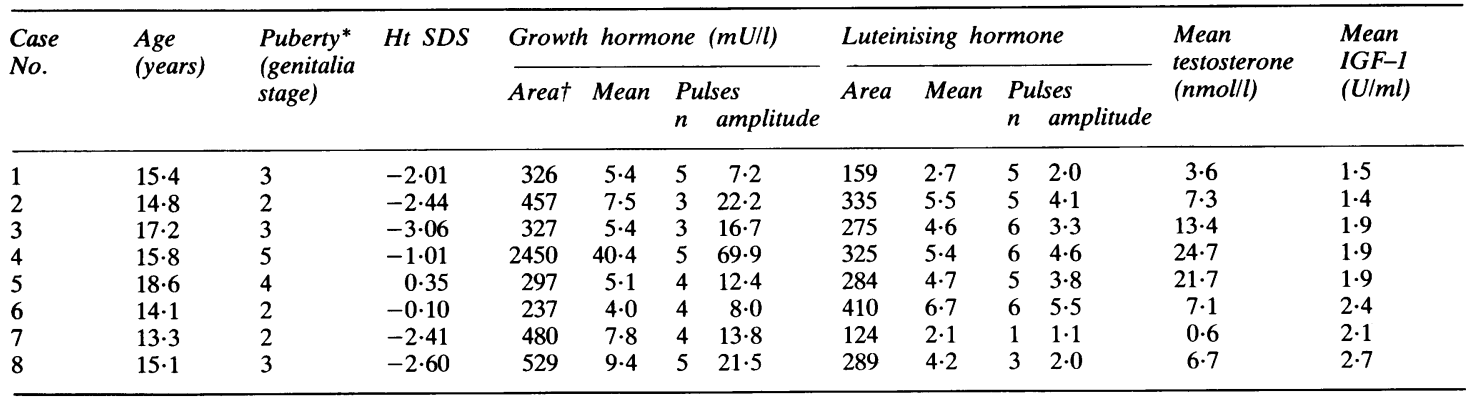

*According to Tanner. ${ }^{10}$

†Units of area under the curve $=\mathrm{mU} / \mathrm{l}$. min per hour of study.

Cases $2,4,6$ were off steroids for $0 \cdot 5,2 \cdot 0$, and $0 \cdot 2$ years, respectively. 

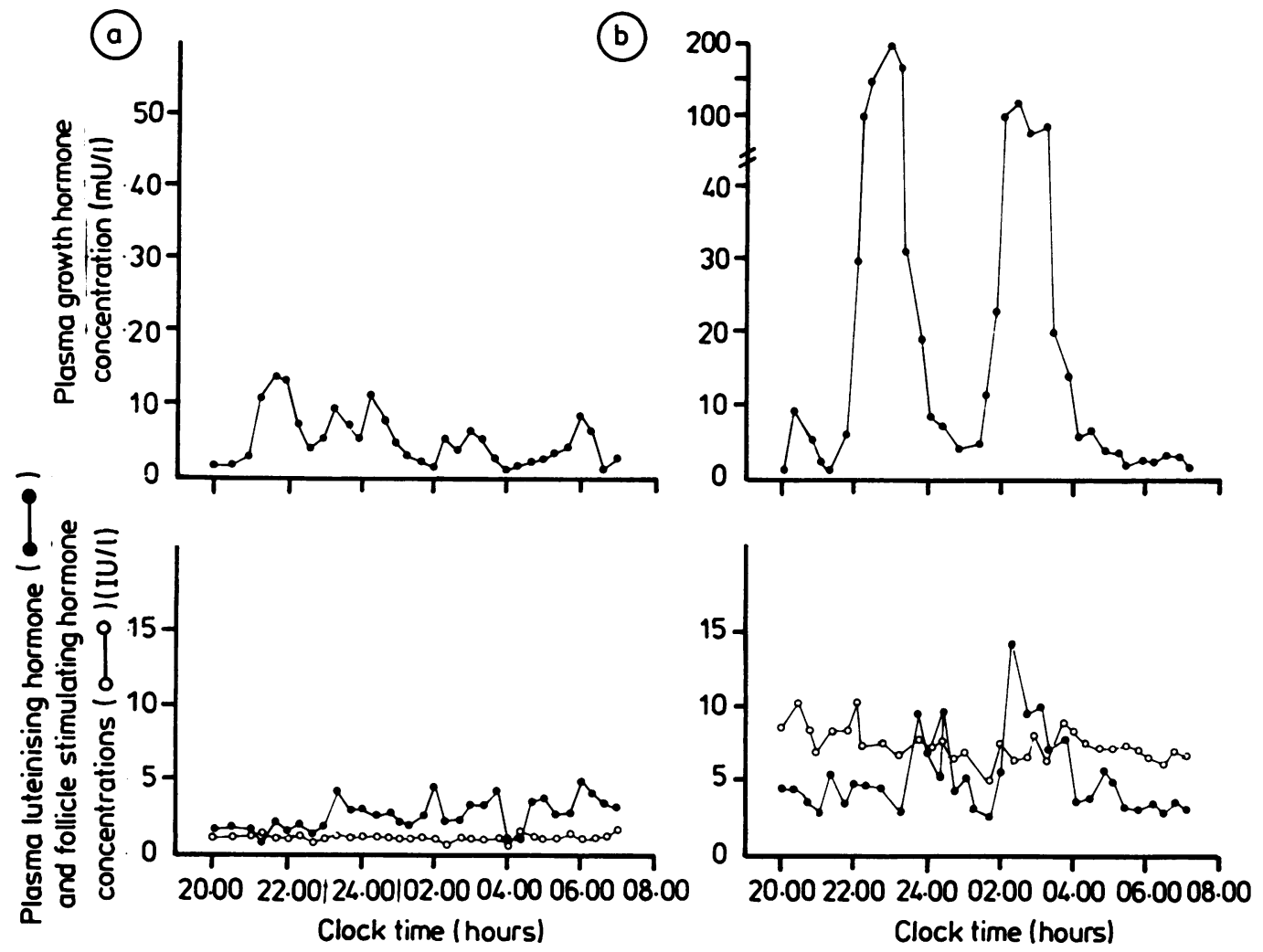

Fig 4 Overnight hormone profile in two adolescent boys with steroid sensitive nephrotic syndrome: (a) patient 1 , table 3 , on continuous treatment since 2.3 years of age; (b) a boy (age 15.8 years) treated from 3.4 years of age, the steroids had been stopped two years previously.

mone and gonadotrophins and his profile is also shown (fig 4b).

Mean testosterone concentration was significantly associated with genital stage $(\mathrm{r}=0 \cdot 82, \mathrm{p}=0 \cdot 013)$, as was growth hormone area under the curve $(r=0 \cdot 74$, $\mathrm{p}=0.037)$. Mean growth hormone amplitude correlated with genital stage but this failed to reach significance at the $5 \%$ level $(r=0.68, p=0.063)$. Mean growth hormone amplitude was associated positively with mean testosterone concentration, but this again failed to reach significance $(r=0.66$, $\mathrm{p}=0 \cdot 076$ ). Mean IGF-1 concentration was within our accepted normal range for this age with no association between IGF-1 concentration and with measurements of growth hormone or with testosterone concentration.

\section{Discussion}

We have shown that long term steroid treatment given through adolescence has an adverse effect on the rate of growth in boys with steroid sensitive nephrotic syndrome despite the use of a low dose alternate day regimen for the major part of the treatment course. We cannot say if this is also true for girls, who have a lower incidence of the syndrome and who, in our experience, require shorter treatment periods.

In boys, Ht SDS was significantly lower after several years of treatment, confirming data from previous studies. ${ }^{2}{ }^{3}$ Other studies have found the effect on growth to be dose related. ${ }^{1236}$ We were unable, in retrospect, to calculate accurately total steroid dose received by each child. If we make the assumption (although we have no statistical data) that the relapse rate reflects the total annual steroid dose, we can find no relation between this and growth retardation.

With increasing chronological age Ht SDS calculated at yearly intervals decreased (fig 3). Obviously it is difficult to disentangle duration of treatment and total steroid dose from an age dependent effect 
as many of the peripubertal children will have been taking steroids for longer. The beginning of a fall in growth velocity at the age of 10 years, however, and its sudden and sharp decline in all the boys at the age of 13 years, combined with the high incidence of delayed appearance of secondary sex characteristics, is strong evidence in favour of an independent effect of steroids on the onset and progression of puberty and the pubertal growth spurt. The pubertal delay is unlikely to be due to the steroid sensitive nephrotic syndrome itself as the children remain free from disease as long as they are having steroid treatment. Furthermore, we have been unable to show a relation between the relapse rate (which we believe is a reflection of the severity of the syndrome) and the $\Delta \mathrm{Ht}$ SDS. In fact, over the age of 10 years the relapse rate is significantly less than before that age, whereas the major effect on growth was seen after 10 years.

We showed no relation between cyclophosphamide and growth problems. Foote et al found no effect of cyclophosphamide on growth, ${ }^{8}$ but it is recognised that it may cause gonadal damage, particularly in boys. ${ }^{20}$ Low plasma androgens but normal gonadotrophins have been reported after a standard single course for steroid sensitive nephrotic syndrome. ${ }^{21}$ Children given cyclophosphamide, however, are usually those showing severe steroidal side effects, so it may be possible to attribute these findings to either drug.

We do not know whether the boys will ultimately reach their genetic height potential. Kerrebijn and De Kroon reported slow and variable catch up growth after stopping steroid treatment in six prepubertal children with asthma. ${ }^{3}$ Trompeter et al found the mean height to be between the 10th and 25 th centiles respectively in six males and four females with steroid sensitive nephrotic syndrome who continued to relapse into adult life. ${ }^{4}$ Foote et al found no significant difference in Ht SDS between 28 postpubertal and 52 prepubertal subjects treated with steroids for the syndrome and the general population, although there were six subjects with $\mathrm{Ht}$ SDS of less than -2 SD. ${ }^{8}$ No information was given as to the number taking steroids during the peripubertal period and the data were not analysed longitudinally. Even if catch up growth was ultimately to occur this is of little consolation to many older boys who may be severely emotionally disturbed by loss of height and physical immaturity relative to their peers.

Overnight profile analysis suggested that steroid treatment considerably affects physiological secretion of hormones, with reduction in pulse amplitude of growth hormone and gonadotrophins. Stopping steroid treatment increases the growth hormone and gonadotrophin concentrations with an increase in the hormone pulse amplitude. The parameters of pulse analysis correlated with mean testosterone concentration and the clinical staging of puberty. No effect was seen on IGF-1 concentration. Men taking long term steroids for asthma have been shown to have significantly reduced levels of testosterone ${ }^{22}$; however, gonadotrophin concentrations have been reported either as normal ${ }^{23}$ or increased. ${ }^{22}$ Our data appear to be the first where physiological patterns of gonadotrophin secretion seem to be abnormally blunted during long term steroid treatment, although blunting of growth hormone pulsatility has been described. ${ }^{24}{ }^{25}$ It has been suggested that the mechanism of growth failure in steroid treatment is through a peripheral action of steroids at the level of the chondrocyte. ${ }^{26}$ Our data from adolescents on long term steroid treatment for nephrotic syndrome suggest that central effects of steroid treatment on the hypothalamic-pituitary axis may be as important in this condition and certainly warrants further investigation.

In summary, we observed that boys with steroid sensitive nephrotic syndrome, who were treated with an alternate day steroid regimen for several years, do not maintain a normal rate of growth. As the growth delay occurs after the age of 10 years and is associated with delayed appearance of secondary sexual characteristics, we suggest that steroids interfere with the onset and progression of puberty and the pubertal growth spurt. Despite the evidence in the literature that final height is usually acceptable, this is a definite clinical problem with associated emotional difficulties. Overnight hormone profile analysis suggests that there is a disturbance of the hypothalamic-pituitary-gonadal axis with blunting of the expected overnight pulsatility of growth hormone and gonadotrophins. A disturbance of hypothalamic-pituitary function may be the major factor in the development of maturational delay and in severe cases this may be amenable to therapeutic agents such as luteinising hormone releasing hormone or anabolic steroids.

This study was supported by the Children's Nationwide Medical Research Fund. SAG is supported by the Wellcome Foundation, PA by grants from Serono Laboratories (UK) and the Child Growth Foundation, and $\mathrm{JJ}$ by a grant from the Adint Trust. We are grateful for Dr C Buchanan for performing the IGF-1 assay, to Mrs Jenkins and Miss G Wilson for the electroencephalography recordings and the sister and nursing staff of Peter Bishop medical ward. We thank Mrs Catherine Bryant for typing the manuscript.

\section{References}

${ }^{1}$ Blodgett FM, Burgin L, Iezzoni D, Gribetz D, Talbot NB. Effects of prolonged cortisol therapy on the statural growth, skeletal maturation and metabolic status of children. $N$ Engl $J$ Med 1956;254:636-41.

2 Lam CN, Arneil GC. Long-term dwarfing effects of corticoster- 
oid treatment for childhood nephrosis. Arch Dis Child 1968;43: 589-94.

${ }^{3}$ Kerrebijn KF, De Kroon JPM. Effect on height of corticosteroid therapy in asthmatic children. Arch Dis Child 1968;43:556-61.

4 Trompeter RS, Lloyd BW, Hicks J, White RHR, Cameron JS. Long-term outcome for children with minimal change nephrotic syndrome. Lancet 1985; i:368-70.

5 Sturge RA, Beardwell C, Hartog M, Wright D, Ansell BM. Cortisol and growth hormone secretion in relation to linear growth: patients with Still's disease on different therapeutic regimens. Br Med $J$ 1970; iii:547-51.

6 Byron MA, Jackson J, Ansell BM. Effect of different corticosteroid on hypothalamic-pituitary-adrenal axis and growth in juvenile chronic arthritis. $J R$ Soc Med 1983;76:452-7.

7 Polito C, Oporto MR, Totino SF, La Manna A, Di Toro R. Normal growth of nephrotic children during long-term alternate-day prednisolone therapy. Acta Paediatr Scand 1986; 75:245-50.

${ }^{8}$ Foote KD, Brocklebank JT, Meadow SR. Height attainment in children with steroid-responsive nephrotic syndrome. Lancet 1985;ii:917-9.

9 Tanner JM, Whitehouse RH, Takaishi M. Standards from birth to maturity for height, weight, height velocity and weight velocity: British Children, 1965. Part II. Arch Dis Child 1966;41:613-35.

10 Tanner JM. Growth at adolescence 2nd ed. Oxford: Blackwell Scientific Publications, 1962.

11 Rechtschaffen A, Kales A. A manual of standardised terminology, techniques and scoring system for sleep stages. Bethesda, Maryland: National Institutes of Health Publication No 204, 1968.

12 Daughaday WH, Mariz IK, Blethen SL. Inhibition of access of bound somatomedin to membrane receptor and immunobinding sites: a comparison of radioreceptor and radioimmunoassay of somatomedin in native and acid-ethanol-extracted serum. J Clin Endocrinol Metab 1980;51:781-8.

${ }^{13}$ Morrell DJ, Ray KP, Holder AT, et al. Somatomedin C/insulinlike growth factor 1: simplified purification procedure and biological activities of the purified growth factor. $J$ Endocrinol 1986;110:151-8.

${ }^{14}$ Merriam GR, Wachter KW. Algorithms for the study of episodic hormone secretion. Am J Physiol 1982;243:E310-8.
${ }^{15}$ Finkelstein W, Roffwarg HP, Boyar RM, et al. Age related change in the twenty-four hour spontaneous secretion of growth hormone. J Clin Endocrinol Metab 1972;35:665-70.

16 Plotnick LP, Thompson RG, Kowanski AA, et al. Circadian variation of integrated concentration of growth hormone in children and adults. J Clin Endocrinol Metab 1975;40:240-5.

17 Zadik Z, Chalew S, McCarter RJ, et al. The influence of age on the 24-hour integrated concentration of growth hormone in normal individuals. J Clin Endocrinol Metab 1985;60:513-6.

18 Lee PA, Plotnick LP, Steele RE, et al. Integrated concentrations of luteinising hormone and puberty. J Clin Endocrinol Metab 1976;43:168-72.

19 Lee PA, Plotnick LP, Migeon CJ, et al. Integrated concentrations of follicle stimulating hormone and puberty. J Clin Endocrinol Metab 1978;46:488-90.

${ }^{20}$ Fairley KR, Barrie JU, Johnson W. Sterility and testicular atrophy related to cyclophosphamide treatment. Lancet 1972; i:568-9.

21 Trompeter RS, Evans PR, Barratt TM. Gonadal function in boys with steroid-responsive nephrotic syndrome treated with cyclophosphamide for short periods. Lancet 1981;i:1177-9.

22 Reid IR, Ibbertson HK, France JT, Pybus J. Plasma testosterone concentrations in asthmatic men treated with glucocorticoids. Br Med J 1985;291:574.

${ }^{23}$ Doerr P, Pirke KM. Cortisol-induced supression of plasma testosterone in normal adult males. $J$ Clin Endocrinol Metab 1976;43:622-9.

${ }^{24}$ Pantelakis SN, Sinaniotis CA, Sbirakis S, et al. Night and day growth hormone levels during treatment with corticosteroids and corticotrophin. Arch Dis Child 1972;47:605-8.

25 Krieger DT, Glick SM. Sleep EEG stages and plasma growth hormone concentration in states of endogenous and exogenous hypercortisolaemia or ACTH elevation. J Clin Endocrinol Metab 1974;39:986-1000.

26 Preece MA. The effect of administered corticosteroids on the growth of children. Postgrad Med J 1976;52:625-30.

Correspondence to Dr L Rees, Department of Paediatrics, 12th Floor, Guy's Tower, Guy's Hospital, London SE1 9RT.

Accepted 8 December 1987 